\title{
$\beta$-catenin represses miR455-3p to stimulate m6A modification of HSF1 mRNA and promote its translation in colorectal cancer
}

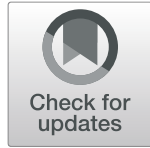

Ping Song ${ }^{1}$, Lifeng Feng ${ }^{2}$, Jiaqiu Li', Dongjun Dai ${ }^{1}$, Liyuan Zhu², Chaoqun Wang ${ }^{3}$, Jingyi Li ${ }^{2}$ Ling Li ${ }^{2}$, Qiyin Zhou', Rongkai Shi ${ }^{1}$, Xian Wang ${ }^{1 *}$ and Hongchuan Jin $^{2^{*}}$

\begin{abstract}
Background: Heat shock transcription factor1 (HSF1) was overexpressed to promote glutaminolysis and activate mTOR in colorectal cancer (CRC). Here, we investigated the mechanism for cancer-specific overexpression of HSF1.

Methods: HSF1 expression was analyzed by chromatin immunoprecipitation, QRT-PCR, immunohistochemistry staining and immunoblotting. HSF1 translation was explored by polysome profiling and nascent protein analysis. Biotin pulldown and m6A RNA immunoprecipitation were applied to investigate RNA/RNA interaction and m6A modification. The relevance of HSF1 to CRC was analyzed in $\mathrm{APC}^{\mathrm{min} /+}$ and $\mathrm{APC}^{\mathrm{min} /+} \mathrm{HSF}^{+/-}$mice.

Results: HSF1 expression and activity were reduced after the inhibition of WNT/ $\beta$-catenin signaling by pyrvinium or $\beta$-catenin knockdown, but elevated upon its activation by lithium chloride (LiCl) or $\beta$-catenin overexpression. There are much less upregulated genes in HSF1-KO MEF treated with LiCl when compared with LiCl-treated WT MEF. HSF1 protein expression was positively correlated with $\beta$-catenin expression in cell lines and primary tissues. After $\beta$-catenin depletion, HSF1 mRNA translation was impaired, accompanied by the reduction of its m6A modification and the upregulation of miR455-3p, which can interact with 3'-UTR of HSF1 mRNA to repress its translation. Interestingly, inhibition of miR455-3p rescued $\beta$-catenin depletion-induced reduction of HSF1 m6A modification and METTL3 interaction. Both the size and number of tumors were significantly reduced in APC $\mathrm{min} /+$ mice when HSF1 was genetically knocked-out or chemically inhibited.

Conclusions: $\beta$-catenin suppresses miR455-3p generation to stimulate m6A modification and subsequent translation of HSF1 mRNA. HSF1 is important for $\beta$-catenin to promote CRC development. Targeting HSF1 could be a potential strategy for the intervention of $\beta$-catenin-driven cancers.
\end{abstract}

Keywords: Colorectal cancer, $\beta$-Catenin, HSF1, Translation, miR455-3p, m6A RNA modification

\footnotetext{
* Correspondence: wangx118@zju.edu.cn; jinhc@zju.edu.cn

'Department of Medical Oncology, Cancer Institute of Zhejiang University, Sir Run Run Shaw Hospital, School of Medicine, Zhejiang University, Hangzhou, China

${ }^{2}$ Labortary of Cancer Biology, Key Lab of Biotherapy in Zhejiang, Sir Run Run Shaw Hospital, School of Medicine, Zhejiang University, Hangzhou, China Full list of author information is available at the end of the article
}

(C) The Author(s). 2020 Open Access This article is licensed under a Creative Commons Attribution 4.0 International License, which permits use, sharing, adaptation, distribution and reproduction in any medium or format, as long as you give appropriate credit to the original author(s) and the source, provide a link to the Creative Commons licence, and indicate if changes were made. The images or other third party material in this article are included in the article's Creative Commons licence, unless indicated otherwise in a credit line to the material. If material is not included in the article's Creative Commons licence and your intended use is not permitted by statutory regulation or exceeds the permitted use, you will need to obtain permission directly from the copyright holder. To view a copy of this licence, visit http://creativecommons.org/licenses/by/4.0/ The Creative Commons Public Domain Dedication waiver (http://creativecommons.org/publicdomain/zero/1.0/) applies to the data made available in this article, unless otherwise stated in a credit line to the data. 


\section{Introduction}

Colorectal cancer (CRC) is the third most common cancer with high mortality rate globally [1]. The accumulation of various genetic and epigenetic changes activates multiple oncogenic signaling critical for the pathogenesis of $\mathrm{CRC}$, such as $\mathrm{WNT} / \beta$-catenin signaling pathway [2]. Its activation will eventually initiate a transcriptiondependent oncogenic process to promote cell cycle progression and apoptosis resistance. While the mechanism for activated $\mathrm{WNT} / \beta$-catenin signaling to promote CRC development has been well-explored, no therapeutics targeting this pathway has been successfully developed.

In addition to proliferation activation and apoptosis resistance, metabolism reprogramming is one of important hallmarks of cancer cells [3]. For example, cancer cells favor glycolysis instead of oxidative phosphorylation for glucose metabolism even in aerobic conditions, which was well-known as Warburg effect $[4,5]$. Pyruvate, the last product of glycolysis, is converted into lactate rather than Acetyl-CoA (acetyl coenzyme A) for TCA (Tricarboxylic acid) cycle or the Krebs cycle. Therefore, targeting enhanced glycolysis has been proposed as novel options in the prevention and treatment of human cancers including CRC [5]. However, as a metabolism hub, TCA cycle is important in both energy production and biosynthesis. Therefore, it needs to be replenished by anaplerotic reactions such as glutaminolysis [6]. Previously, we reported that heat shock transcription factor 1 (HSF1) stimulated glutaminolysis to activate mTOR and promote CRC development by upregulating the expression of glutaminase 1 (GLS1), the critical enzyme in glutaminolysis [7]. HSF1 expression was increased in CRC and had a positive correlation with shorter disease-free survival (DFS). However, the upstream mechanism for HSF1 overexpression in CRC was still unclear.

Gene expression can be controlled by multiple processes including transcription, mRNA degradation, translation and protein degradation. While gene translation and protein degradation have been extensively investigated, more and more studies focused on mRNA translation by exploring the effect of non-coding RNAs such as microRNAs (miRNAs) and new modifications of mRNA including N6methyladenine (m6A) modification $[8,9]$. MiRNAs can form a miRNA-induced silencing complex (miRISC) to posttranscriptionally regulate gene expression by inhibiting cap-dependent initiation and stimulating mRNA deadenylation $[10,11]$. On the other hand, as one of the most abundant modifications in mRNA, m6A modification of mRNAs usually promotes translation by recruiting initiation factors such as eIF3 to the $5^{\prime}$ end of the mRNA [12]. While miRNAs and mRNA m6A modifications play a distinct role in mRNA translation, the interplays between them were not clarified.
In this study, we found that activated $\mathrm{WNT} / \beta$-catenin signaling stimulated HSF1 translation to promote CRC development by repressing HSF1 mRNA-targeting miR455-3p to increase m6A modification of HSF1 mRNA. Therefore, targeting HSF1 translation could be a new strategy for the intervention of CRC and other cancers driven by activated $\mathrm{WNT} / \beta$-catenin signaling.

\section{Materials and methods}

Cell, antibodies, and chemicals

Human CRC cell lines SW480, SW620, DLD1, RKO were obtained from the American Type Culture Collection (ATCC). All cells were routinely cultured in RPMI 1640 (Invitrogen; 11875-093) or DMEM (Invitrogen; 11965-092) supplemented with $10 \%$ fetal bovine serum. All cells were incubated at $37^{\circ} \mathrm{C}$ with $5 \% \mathrm{CO} 2$ and $95 \%$ humidity. The following antibodies were used for western blotting and IHC: HSF1 (12972S, Cell Signaling Technology, CST; ab52757, Abcam); $\beta$-catenin (8480S, CST); $\beta$-actin (4970 L, CST); FLAG (F1804-1, Sigma); cyclinD1 (ab134175, Abcam); Cleaved PARP1 (9541-s, CST); METTL3 (a8370, Abclonal); GLS1 (ap8809b, Abgent). Pyrvinium (P0027), LiCl (793620), cycloheximide (R750107), chloroquine (C6628), MG132 (474790) and PD150606 (D5946) were purchased from SigmaAldrich.

\section{SiRNA, miRNA mimics/inhibitors transfection}

Small interfering RNA (siRNA) targeting $\beta$-catenin, METTL3 and microRNAs were synthesized by Genepharma (Shanghai, China) and RiboBio (Guangzhou, China). The sequence of these siRNAs and miRNAs were listed in Additional file 1: Table S1. SiRNAs and miRNA mimics/inhibitors were transfected into cells seeded overnight by lipo2000 (Invitrogen, USA) or Lipofectamine RNAiMax transfection reagent (Invitrogen, USA), according to the manufacturer's instructions.

\section{Luciferase activity assay}

The plasmid of $\beta$-catenin reporter was gifted from Prof. Ximei Wu (Zhejiang University). For HSF1 activity assay, a fragment containing $3 \mathrm{X}$ HSE were synthesized and inserted into the PGL3-basic vectors (Promega Corporation, USA). The plasmid was co-transfected with pRL renilla and $\beta$-catenin siRNA by using lipo2000 (Invitrogen, USA) or treatment with pyrvinium by X-treme GENE HP DNA Transfection Reagent (Roche, USA). 3'UTR segment of the HSF1 was cloned by PCR and inserted into the vector pMIR-REPORTER (Promega). The mutation of miR455 binding sites in HSF1 3'-UTR was generated by Quick Site-Directed Mutagenesis (600674-51, Stratagene, USA). The resultant plasmids were co-transfected with pRL renilla and miR455 mimics by using lipo2000 (Invitrogen, USA). $48 \mathrm{~h}$ post- 
transfection, the luciferase activity was measured by the Dual-GLO Luciferase Assay System (Promega Corporation, USA).

\section{Chromatin immunoprecipitation (ChIP)}

ChIP analysis was conducted with the SimpleChIP ${ }^{\text {ix }}$ Enzymatic Chromatin IP Kit (CST, USA). Antibodies used were anti-HSF1 (12972S, CST), TCF7L2(C48H11, CST) and FLAG (F1804-1, Sigma). The primers used for the PCR analysis of precipitated DNA were shown in Additional file 1: Table S2. For FLAG-ChIP assay, the flag- $\beta$-catenin vector was transiently overexpressed by transfection. After $48 \mathrm{~h}$, the enrichment of flag- $\beta$-catenin on COL27A1 promoter was measured by the ChIP Kit.

\section{Immunoblotting and immunohistochemistry}

Immunoblotting and immunohistochemistry (IHC) assays were performed as previously reported [7]. For Immunoblotting, total proteins were extracted with RIPA buffer supplemented with protease inhibitors (Roche, USA). After heating the protein sample to $95-100^{\circ} \mathrm{C}$ for $20 \mathrm{~min}$, cell lysates were transferred to polyvinylidene fluoride (PVDF) membranes. After the membranes were blocked in $5 \%$ milk, primary antibody with gentle agitation overnight at $4{ }^{\circ} \mathrm{C}$.

For IHC assay was performed in a tissue array containing 80 cases of colonic tissues. Primary antibodies used were listed above. The degree of immunostaining was assessed by 2 independent pathologists and evaluated by assigning a score of $0-3$. Scores were defined as follows: 0 , no staining; 1 , faint staining; 2 , moderate staining and 3 , strong staining. Final scores of 0 and 1 were regarded as low expression, whereas scores of 2 and 3 considered as high expression.

\section{Apoptosis detection}

Cell apoptosis was measured by flow cytometry analysis and western blotting. For flow cytometry analysis of apoptosis, cells were harvested and re-suspended in $100 \mu \mathrm{l} 1 \mathrm{x}$ binding buffer. $5 \mu \mathrm{l}$ fluorescein isothiocyanate (FITC) annexin V and propidium iodide (PI) (556,547; BD Biosciences, USA) were added to the cell suspension and then incubated for $15 \mathrm{~min}$ at room temperature. After that, the samples were attenuated with $400 \mathrm{ul} 1 \mathrm{x}$ binding buffer and analyzed by ACS Calibur flow cytometer.

\section{Puromycin-labelling}

To detect the change of nascent HSF1 synthesis, $2 \times 10^{6}$ cells were plated in $10 \mathrm{~cm}$ dish. After the given treatment, cells were incubated with 1:1000 Biotin-dCpuromycin (NU-925-BIO-S, Jena Bioscience) for $24 \mathrm{~h}$. Cells were lysed with $1 \%$ NP40 buffer $(20 \mathrm{mM}$ Tris- $\mathrm{HCl}$, $\mathrm{PH} \quad 7.4, \quad 150 \mathrm{mM} \quad \mathrm{NaCl}, \quad 1 \% \quad \mathrm{NP} 40, \quad 10 \%$ glycerol) containing $1 \mathrm{X}$ protease inhibitor cocktail. After adequate centrifugation, the supernatant was incubated with 80ul streptavidin sepharose beads (GE17-5113-01, Sigma) by rotating at $4{ }^{\circ} \mathrm{C}$ for $6 \mathrm{~h}$ to overnight. The mixture was washed by $1 \%$ NP40 buffer for 5 times and subjected to western blotting using HSF1 antibody.

\section{Polysome profiling}

Polysome profiling separates translating or nontranslating mRNAs on a sucrose gradient according to the number of bound ribosomes as previously described [13]. In brief, cells were grown to $\sim 80 \%$ confluence. Before collection, cells were incubated with $100 \mu \mathrm{g} / \mathrm{ml}$ of cycloheximide for $15 \mathrm{~min}$. Then cells are lysed by polysome buffer [ $200 \mathrm{mmol} / \mathrm{L} \mathrm{KCl}, 15 \mathrm{mmol} / \mathrm{L} \mathrm{MgCl} 2,1 \%$ Triton X100, $100 \mu \mathrm{g} / \mathrm{mL}$ cycloheximide, $20 \mathrm{mmol} / \mathrm{L}$ heparin, and $100 \mathrm{U} / \mathrm{mL}$ RNase Inhibitor (Takara), 1X cocktail] for $15 \mathrm{~min}$ on ice, lysates were centrifuged $(14,000$ $\mathrm{rpm}$ for $15 \mathrm{~min}$ ), and the supernatant was layered onto a 5 to $50 \%$ sucrose gradient. Gradients were then centrifuged at $38,000 \mathrm{rpm}$ for $130 \mathrm{~min}$ at $4{ }^{\circ} \mathrm{C}$ and polysomebound fractions were collected using an ISCO Density Gradient Fractionation System (ISCO, Lincoln, NE) with continuous monitoring based on A260nm wavelength. The RNA in each fraction was extracted using Trizol reagent (Invitrogen) and analyzed by real-time RT-PCR.

\section{Biotin pull down assay}

Biotin pull down assay was performed as described previously [14]. Cells were transfected with biotinylated miR455-3p probes for $48 \mathrm{~h}$ and resuspended using lysis buffer $(20 \mathrm{mM}$ Tris, pH 7.5, $200 \mathrm{mM} \mathrm{NaCl}, 2.5 \mathrm{mM}$ $\mathrm{MgCl} 2,60 \mathrm{U} / \mathrm{mL}$, SUPERase-In, $1 \mathrm{mM}$ DTT, 0.05\% Ige$\mathrm{pal}$, protease inhibitors). Lysates were incubated with prepared streptavidin beads (GE Healthcare). Yeast tRNA (Sigma) was used for blocking lysates at $4{ }^{\circ} \mathrm{C}$ for 3 h. Then washed 5 times with binding and wash buffer (5 mM Tris- $\mathrm{HCl}, \mathrm{pH} 7.5,0.5 \mathrm{mM}$ EDTA, $1 \mathrm{M} \mathrm{NaCl}$ ). Finally, the bound RNAs were extracted and purified for qPCR.

\section{RNA immunoprecipitation (RIP) assay}

RIP assay was performed by Magna RIPTM RNABinding Protein Immunoprecipitation Kit (Millipore, No.17-700). Briefly, $2 \times 10^{7}$ cells were lysed in $100 \mu \mathrm{l}$ RIP lysis buffer and immunoprecipitated with antibodies of interest and protein $\mathrm{G}$ magnetic beads at $4{ }^{\circ} \mathrm{C}$ overnight, followed by six times of washes in Washing Buffer and protein digestion at $55^{\circ} \mathrm{C}$. Total RNA was isolated and subjected to RT-PCR analysis. Following antibodies were used for RIP: N6-methyladenosine (202, 003, synaptic); METTL3 (a8370, Abclonal); IgG (2,912, 787, Millipore). 


\section{RNA-sequencing}

$2 \mathrm{X} 10^{6}$ WT MEF and HSF1 KO MEF were plated and cultured overnight. Following day, cells were treated with $20 \mathrm{mM} \mathrm{LiCl}$ for $48 \mathrm{~h}$. Cells were collected with Trizol reagent. The total RNA was processed by NEBNext ${ }^{\circ}$ Poly(A) mRNA Magnetic Isolation Module to enrich mRNA, and the product RNA was used for construction Library, via KAPA Stranded RNA-Seq Library Prep Kit (Illumina). Sequencing libraries, denatured by $0.1 \mathrm{M}$ $\mathrm{NaOH}$ to generate single-stranded DNA, as amplified in situ Illumina cBot (TruSeq SR Cluster Kit v3-cBot-HS (\# GD-401-3001, Illumina)). The ends of the generated fragments were used to run 150 Cycles by the Illumina HiSeq 4000 Sequencer. All the experimental steps after the RNA extraction were conducted in Kangcheng Biotechnology Co., Ltd. (Aksomics), Shanghai, China. RNAsequencing was performed three times.

\section{Animal experiments}

Animal care and experiments were conducted in compliance with Institutional Animal Care and Use Committee and NIH guidelines. The C57BL/6 J mice and $\mathrm{Apc}^{\mathrm{min} /+}$ mice were purchased from Model Animal Research Center of Nanjing University (MARC, Nanjing, China). HSF1 KO mice reported previously were used to generate $\mathrm{Apc}^{\mathrm{min} /+}$ mice $\mathrm{HSF}^{+/-}$[7]. Subsequently, 4 groups of mice, wild type, $\mathrm{Apc}^{\mathrm{min} /+}, \mathrm{Apc}^{\mathrm{min} /+} \mathrm{HSFl}^{+/-}$and Apc$\mathrm{min} /+$ treated with KNK437 as previously reported [7], were fed with high-fat diet (45 Kcal\% Fat) for 3 months. The intestine was dissected, flushed with PBS and cut open longitudinally along the main axis. The number of tumors was counted and the sizes of tumors were measured.

\section{Statistics}

All data were expressed as mean \pm SD. Unless specified, the Student's t-test was performed for statistical significance analysis. $P$ value $<0.05$ was considered as statistically significant.

\section{Results}

\section{$\beta$-Catenin activates HSF1 in CRC}

In an effort to explore potential regulations of HSF1, we screened chemicals generating a gene expression pattern similar to HSF1 depletion by connective map (http:// portals.broadinstitute.org/cmap/) $[7,15,16]$. Interestingly, a recently reported inhibitor of WNT/ $\beta$-catenin signaling, pyrvinium, had a similar effect on genomewide gene expression as HSF1 depletion [17] (Fig. 1a and Additional file 2, Fig.S1A-B). Moreover, the expression signature related to $\mathrm{WNT} / \beta$-catenin signaling [18] was positively correlated with the HSF1 signature [15] (Fig. 1b), indicating a potential connection of HSF1 with $\mathrm{WNT} / \beta$-catenin signaling. Indeed, pyrvinium attenuated the activity of a luciferase reporter driven by HSF1 binding sites (HSE, heat shock response elements) $[19,20]$ (Fig. 1c) and reduced the expression of well-known transcriptional targets of HSF1 such as HSP90AA1, HSPA4, HSPB1, and HSPH1 (Fig. 1d and Additional file 2, Fig.S1C). Chromatin immunoprecipitation (ChIP) assay further confirmed the reduced interaction of HSF1 with its transcriptional targets (Fig. 1e and Additional file 2, Fig.S1D). In consistence with pyrvinium, knock-down of $\beta$-catenin by siRNA also decreased HSF1 activity (Fig. 1f), reduced the expression of HSF1 targets (Fig. 1g and Additional file 2, Fig.S1E) and attenuated the interaction of HSF1 with its targets (Fig. 1i and Additional file 2, Fig.S1F). Furthermore, HSF1 targets were upregulated by the potent GSK3 $\beta$ inhibitor $\mathrm{LiCl}$ in colorectal cancer cell line $\mathrm{RKO}$, which had a low level of $\beta$-catenin expression (Fig. 1h).

To explore the biological relevance of HSF1 activation to $\beta$-catenin signaling, we profiled gene expression of wild type mouse embryonic fibroblasts (WT MEF) and HSF1 knock-out MEF (HSF1 KO MEF) before and after $\mathrm{LiCl}$ treatment (NCBI GEO: GSE151119). While only 750 genes were upregulated in $\mathrm{LiCl}$ treated-HSF1 KO MEF, there were 1435 genes significantly upregulated in WT MEF after LiCl treatment (Fig. 1j). Among them, 875 genes displayed a dependence on HSF1 since their expression levels failed to be upregulated by $\mathrm{LiCl}$ treatment once HSF1 was depleted (Fig. 1k). In fact, their expression levels had a high correlation with the expression of a previously reported HSF1 signature (Fig. 11). Furthermore, 368 (42\%) genes had a HSE (Heat shock response element, HSE) within their promoter regions (Fig. $1 \mathrm{~m}$ and Additional file 3), meaning that they are most likely bona fide targets of HSF1. Indeed, some of them such as Tma16, Dedd2, Hspa9 and Kif21a have been confirmed as the target of HSF1 by ChIP-seq (NCBI GEO: GSE57398) (Fig. 1n and Additional file 2, Fig.S1G). Taken together, these results indicated that $\beta$ catenin can positively regulate HSF1.

\section{$\beta$-Catenin stimulates HSF1 protein translation}

To delineate how $\beta$-catenin regulates HSF1, we quantitated protein levels of HSF1 before and after inhibiting $\beta$-catenin. Both pyrvinium and $\beta$-catenin depletion reduced the protein level of HSF1 (Fig. 2a and b). In contrast, overexpression of exogenous $\beta$-catenin increased HSF1 protein level (Fig. 2c). Furthermore, HSF1 protein level was increased after activating $\mathrm{WNT} / \beta$-catenin signaling by $\mathrm{LiCl}$ treatment in both RKO and MEF cells (Fig. 2d). In addition, HSF1 expression correlates well with $\beta$-catenin expression in primary tissues (Fig. $2 \mathrm{e}$ and f, $p<0.01$, Chi-Square Test). All of these data indicated that $\beta$-catenin upregulates HSF1 protein expression. 
A

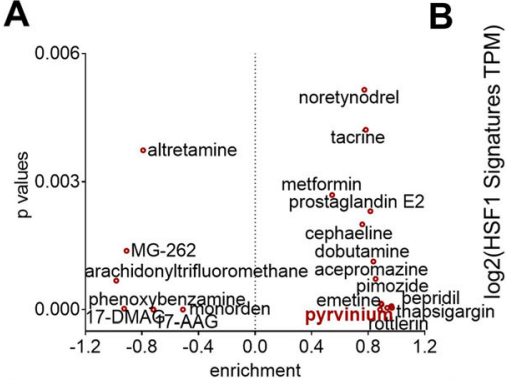

D

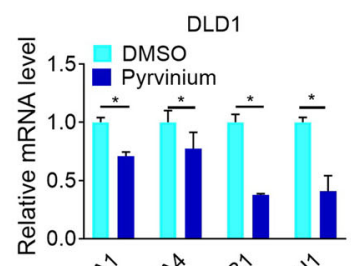

G<smiles>C=CC=CC=CC=CC</smiles>

G

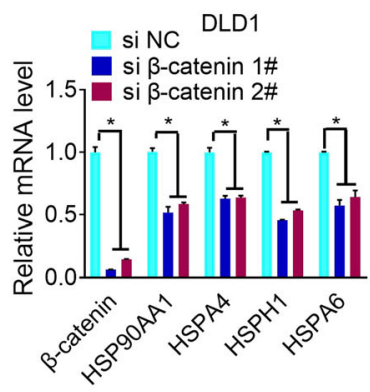

$\mathbf{J}$

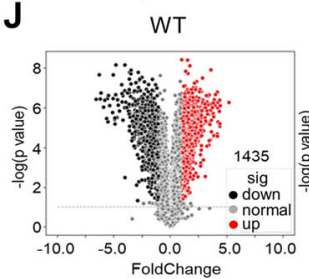

M

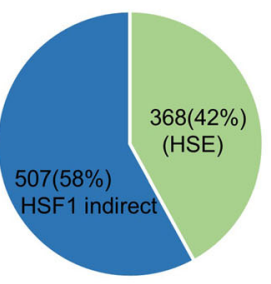

N
E

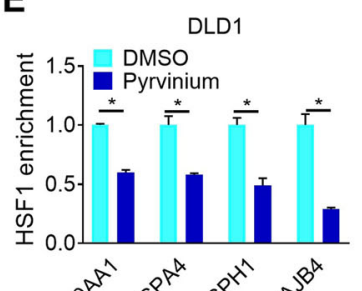

C
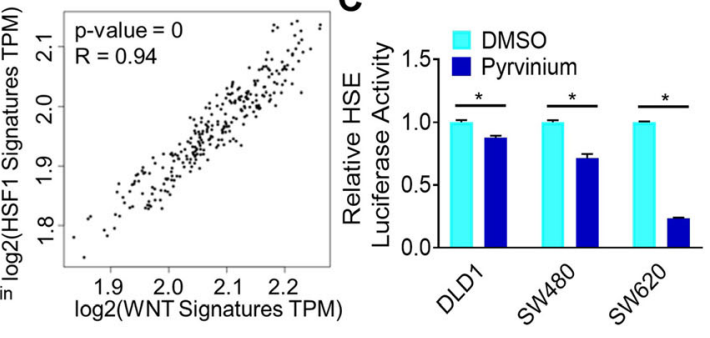

F

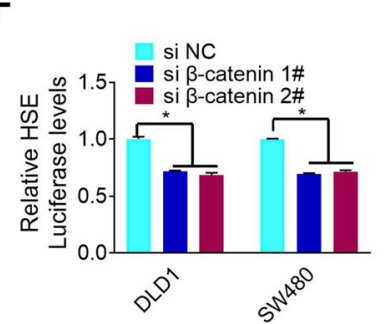

H

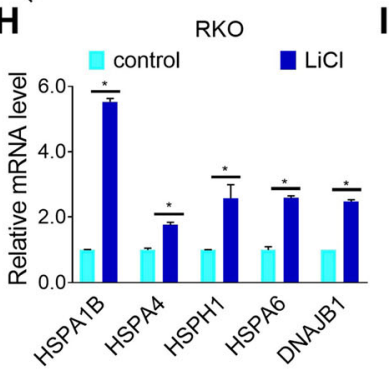

K

$\begin{array}{lll}\text { K } & \text { Kо WT }\end{array}$

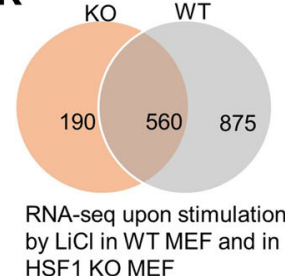

L
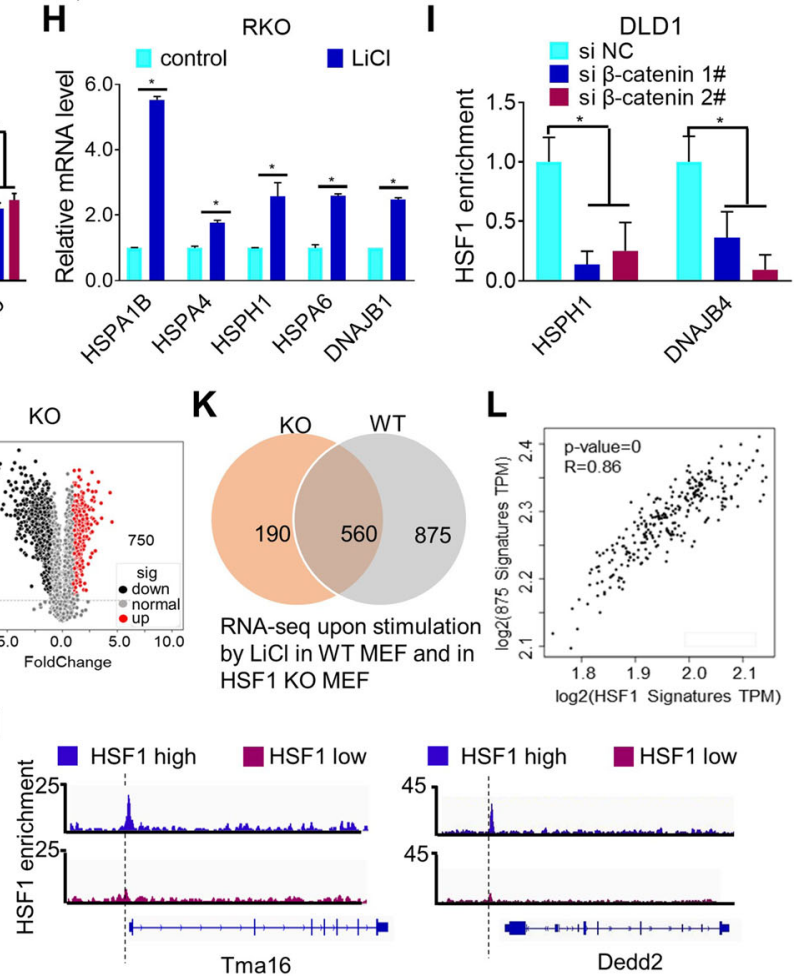

Fig. 1 WNT/ $\beta$-catenin signaling activates HSF1. a Chemicals influencing gene expression in a similar manner to HSF1 inhibition were screened by connective map analysis. $\mathbf{b}$ The correlation of WNT/ $\beta$-catenin signaling signature and HSF1 signature was detected by GEPIA. $\mathbf{c}$ The effect of Pyrvinium on HSE-driven promoter activity was explored by luciferase reporter assay. $\mathbf{d}$ The effects of Pyrvinium on the targets of HSF1 were analyzed by RT-PCR. e Binding of HSF1 to the promoters of HSF1 targets in CRC cells treated with or without Pyrvinium was determined by ChIP. $\mathbf{f}$ The luciferase assays of HSE before and after $\beta$-catenin knockdown were shown as in C. $\mathbf{g}$ and $\mathbf{h}$ The mRNA levels of HSF1 targets with $\beta$ catenin knockdown or LiCl treatment were analyzed by RT-PCR. i Binding of HSF1 to its targets promoter in CRC cells before and after $\beta$-catenin knockdown was analyzed by ChIP. $\mathbf{j}$ Volcano plot displays differentially regulated genes in dHSF1 compared to WT parental cells with LiCl. Red dots indicate significantly regulated genes based on adjusted $p$-value and log-fold change (logFC) $(p<0.01, \log 2 \mathrm{FC}>2)$. $\mathbf{k}$ Differential gene expression analysis in WT and HSF1+/- MEF treated with LiCl were performed by RNA-seq. Numbers of upregulated genes in two cells were shown in Venn graph. I The correlation of 875 putative HSF1-dependent genes from K with reported HSF1 signature was detected by GEPIA. $\mathbf{m}$ Numbers of 875 putative HSF1-dependent genes with or without HSE in their promoters were summarized. $\mathbf{n}$ Representative HSF1 ChIP-seq tracks (NCBI GEO: GSE57398) for 368 HSE-containing genes are shown. Asterisks (*) indicate $p<0.05$ 
A

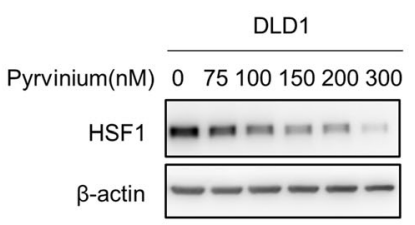

B

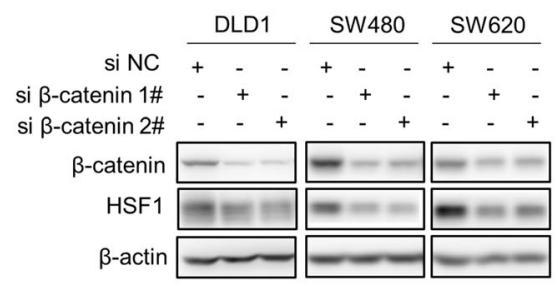

E

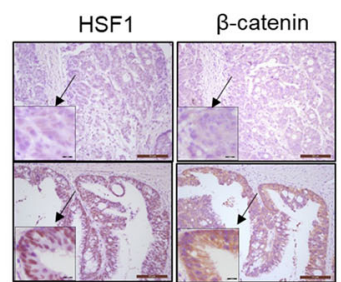

G

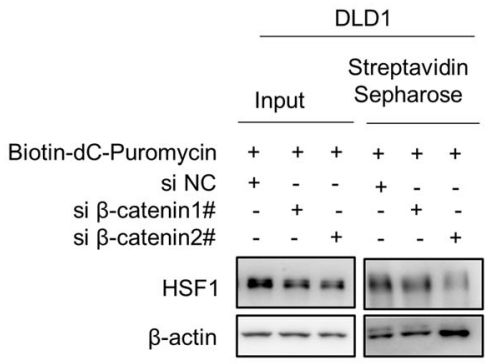

H

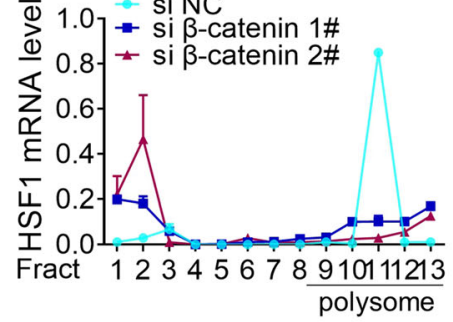

sw620

075100150200300

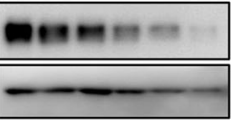

D

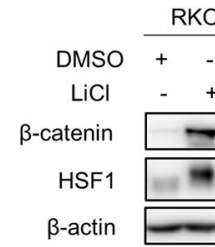

F

\begin{tabular}{|c|c|c|}
\hline \multicolumn{2}{|c|}{$\beta$-catenin-low } & $\beta$-catenin-high \\
\hline HSF1-low & 10 & 8 \\
\hline HSF1-high & 8 & 54 \\
\hline
\end{tabular}

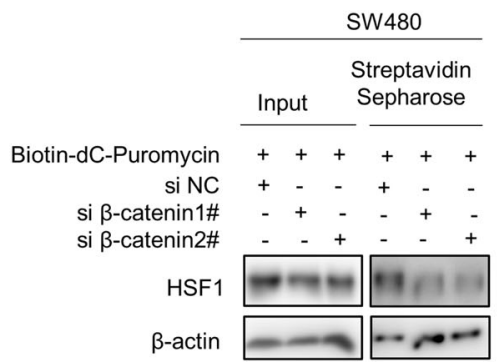

SW480

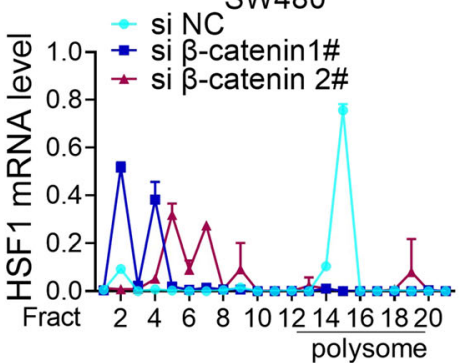

Fig. $2 \beta$-catenin stimulates HSF1 protein translation. a The effect of Pyrvinium on the protein expression of HSF1 was explored by western blotting. $\mathbf{b}$ The effect of $\beta$-catenin knockdown on HSF1 protein level was analyzed by western blotting. $\mathbf{c}$ The protein level of HSF1 before and after $\beta$-catenin overexpression was analyzed by western blotting. $\mathbf{d}$ The effect of LiCl on HSF1 protein level in RKO and MEF was analyzed by western blotting. e The expression of $\beta$-catenin and HSF1 in colorectal tissue was analyzed by immunohistochemistry staining. $\mathbf{f}$ The correlation between $\beta$-catenin expression and HSF1 expression in colorectal tissue was analyzed by chi-square test $\left(^{*} p<0.01\right)$. $\mathbf{g}$ The effect of $\beta$-catenin depletion on HSF1 with puromycin labeling was determined by western blotting. $\mathbf{h}$ Amount of HSF1 mRNA in various polysome fractions was analyzed by $\operatorname{RT}-\mathrm{PCR}\left({ }^{*} p<0.05\right)$

However, there were no apparent alterations in HSF1 mRNA level after $\beta$-catenin knockdown or pyrvinium treatment (Additional file 2, Fig.S2A and S2B). Meanwhile, the half-life of HSF1 protein was also not changed before and after $\beta$-catenin knockdown (Additional file 2, Fig.S2C). Inhibitors of proteasome, autophagy and calpains all failed to reverse HSF1 protein downregulation induced by $\beta$-catenin knockdown (Additional file 2, 
Fig.S2D). All of these results implied that $\beta$-catenin affects HSF1 protein expression most-likely via translation regulation. Therefore, puromycin labeling assay was employed to monitor the synthesis of nascent HSF1 protein [21]. As expected, the puromycin labeling of HSF1 was reduced by $\beta$-catenin depletion (Fig. $2 \mathrm{~g}$ ). To further confirm it, mono/polysome fractions from cytoplasmic extracts of CRC cells before and after $\beta$-catenin depletion were collected by sucrose gradient centrifugation. The subsequent RT-PCR analysis revealed that $\beta$-catenin depletion considerably reduced the presence of HSF1 mRNA in the polysome fraction but increased in nontranslating ribosome fractions (Fig. 2h). In summary, $\beta$ catenin upregulates HSF1 expression by stimulating HSF1 protein translation.

\section{HSF1 protein translation is regulated by miR455-3p}

As microRNAs (miRNAs) play an important role in regulating the efficiency of protein translation, we wondered whether HSF1 protein translation was regulated by microRNAs. Based on bioinformatics screening by TargetScan, miRDB and StarBase, some microRNAs including miR455-3p, miR214-5p, miR431-5p, miR184, miR490-3p, and miR375 were proposed to target $3^{\prime}$ UTR of HSF1 mRNA (Fig. 3a). After functional validation by western blotting, miR455-3p and miR214-5p, but not other microRNAs, were capable to suppress the expression of HSF1 protein in CRC cells (Fig. 3b and Additional file 2, Fig.S3A). However, miR214-5p but not miR455-3p also reduced HSF1 mRNA level (Additional file 2, Fig.S3B). What's more, an inhibitor of miR455-3p rather than miR214-5p rescued the downregulation of HSF1 protein by $\beta$-catenin knockdown (Fig. $3 c$ and Additional file 2, Fig.S3C), indicating that miR455-3p might be relevant to $\beta$-catenin-involved regulation of HSF1 protein translation. Indeed, miR455-3p inhibited the activity of luciferase driven by wild type HSF1 mRNA 3'UTR but not its mutant unable to bind miR455-3p (Fig. 3d). The interaction of miR455-3p with HSF1 mRNA was further confirmed by biotin pull down assay (Fig. 3e). Based on the analysis of TCGA data (http://mirtv. ibms.sinica.edu.tw/), the expression of miR455-3p is lower in colon adenocarcinoma than in normal tissues (Additional file 2, Fig.S3D). Similarly, qPCR analysis revealed lower levels of miR455-3p in CRC tissues than in adjacent non-tumor tissues (Fig. 3f). Additionally, we had confirmed high expression of HSF1 in the same cohort of human CRC tissues previously [7]. Indeed, miR455-3p expression was negatively correlated with the expression of HSF1 (Fig. 3g). On the other hand, miR455-3p, similar to HSF1 inhibition as we reported recently [7], reduced the expression of HSF1 targets, induced the viability inhibition and apoptosis activation of colorectal cancer cells (Fig. 3h-j and Additional file 2,
Fig.S3E-G). The seed sequence of microRNAs was important for targeting mRNA by base-pairing [22]. Indeed, the seed sequence mutant of miR455-3p could not downregulate the protein level of HSF1 (Additional file 2, Fig.S4A), confirming the importance of miR455-3p to target HSF1 protein expression. In a word, miR455-3p targets HSF1 mRNA 3'-UTR to inhibit its translation.

\section{m6A modification of HSF1 mRNA stimulates its protein translation}

In addition to microRNA, mRNA modifications such as N6-methyladenosine (m6A) play important roles in the regulation of HSF1 translation. Interestingly, we noticed that the matching sites of miR455-3p seed sequence in HSF1 mRNA 3'-UTR contains a typical motif of m6A modification (Fig. 4a), which was supported by bioinformatic analysis (http://www.cuilab.cn/sramp) (Fig. 4b and Additional file 2, Fig.S4B). Moreover, we have done the MeRIP sequencing in SW620 and found that the 3'UTR region of HSF1 has one m6A modification site. Intriguingly, this sequence is completely complementary to the seed sequence of miR455-3p (Additional file 2, Fig.S4C). PCR analysis after meRIP (m6A RNA immunoprecipitation) further confirmed m6A modification of HSF1 mRNA (Fig. 4c). What's more, the activity of luciferase driven by the mutant HSF1 mRNA 3'-UTR, which was unable to bind miR455-3p but retains the m6A modification site sequence DRACH $(\mathrm{D}=\mathrm{A}, \mathrm{G}$ or $\mathrm{U} ; \mathrm{R}=$ A or $\mathrm{G} ; \mathrm{H}=\mathrm{A}, \mathrm{U}$ or C) [23-25], was higher than the activity of luciferase driven by wild type HSF1 mRNA 3'-UTR (Fig. 3d), indicating the importance of m6A modification to HSF1 expression. As the main component of the methyltransferase "writer" complex [26, 27], METTL3 was also bound to HSF1 mRNA (Fig. 4d). Once its expression was depleted, m6A modification of HSF1 mRNA was decreased (Fig. 4e). In consistence with its potential roles in promoting protein translation, such a reduction of HSF1 mRNA m6A modification reduced HSF1 protein expression (Fig. 4f) and nascent HSF1 protein synthesis (Fig. 4g). Furthermore, METTL3 depletion considerably reduced the presence of HSF1 mRNA in the polysome fraction but increased in nontranslating ribosome fractions (Fig. 4h), while HSF1 mRNA or the stability of HSF1 protein were not changed (Additional file 2, Fig.S4D and S4E). Moreover, HSF1 protein was decreased with the knockdown of YTHDF1, which was the reader protein of HSF1 m6A modification (Fig. 4i). To sum up, m6A modification of HSF1 mRNA was relevant to stimulate its translation.

\section{$\beta$-Catenin suppresses miR455-3p to increase HSF1 mRNA m6A modification}

Next, we explored the interplay between miR455-3p and m6A modification of HSF1 mRNA. Both HSF1 mRNA 


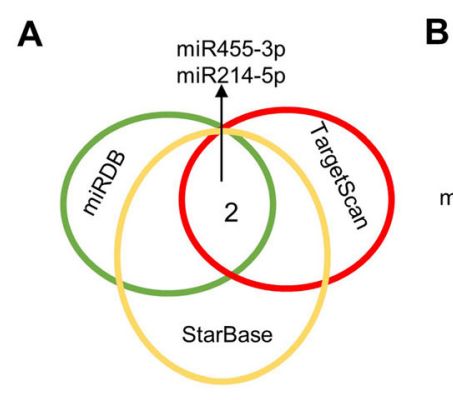

B

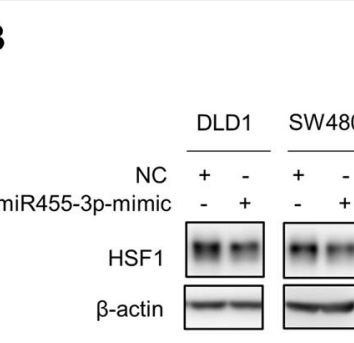

C

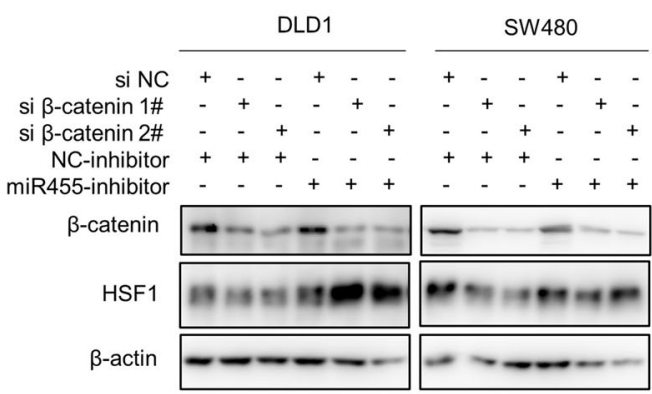

F

G

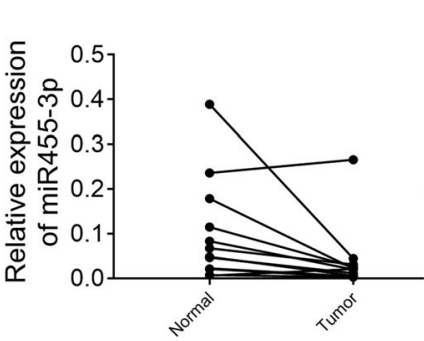

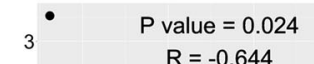

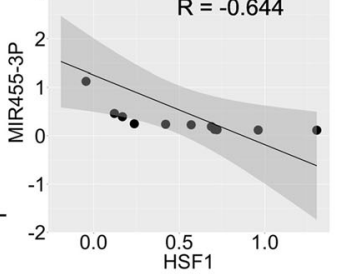

D miR455-3p binding site

WT: CACCTGGACTGAC

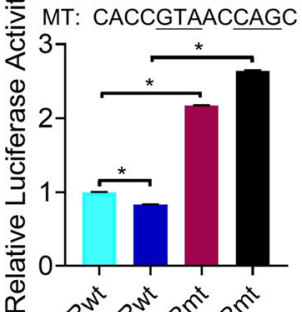

这

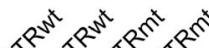

3

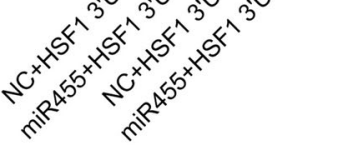

E

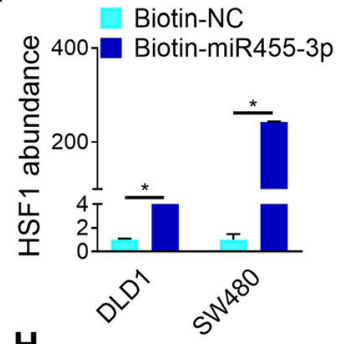

H

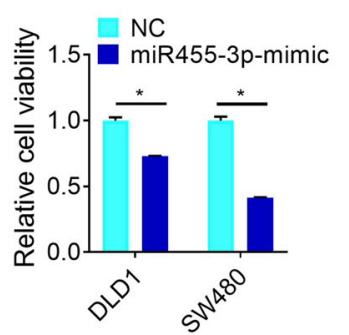

\section{I}
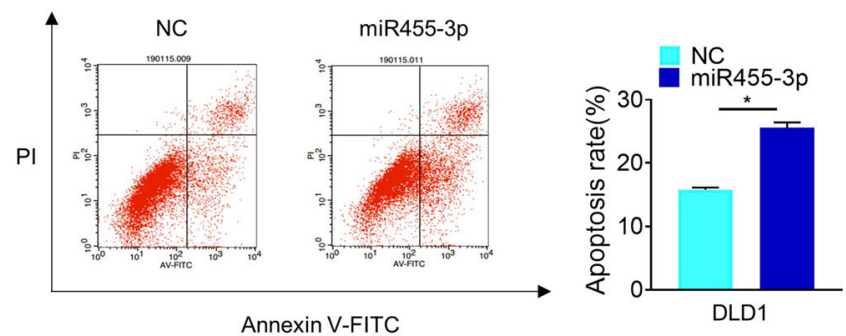

J

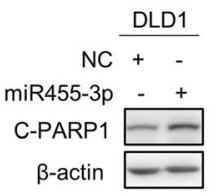

Fig. 3 HSF1 protein translation is regulated by miR455-3p. a Overlap of HSF1-targeting microRNAs predicted by TargetScan, miRDB and StarBase. b The effect of miR455-3p on HSF1 protein was analyzed by western blotting. $\mathbf{c}$ The effect of miR455-3p inhibitor on $\beta$-catenin knockdowninduced HSF1 downregulation was determined by western blotting. $\mathbf{d}$ Luciferase activity assay was used to analyze the effect of miR455-3p on the activity of $3^{\prime}-U T R$ with or without miR455-3p binding sites ( ${ }^{*} p<0.05$ ). e The binding between biotin-miR455-3p and HSF1 mRNA was determined by biotin pull down assay $\left.{ }^{*} p<0.05\right)$. $\mathbf{f}$ Expression of miR455-3p in 12 pairs of fresh CRC tissues and adjacent non-tumor tissues was analyzed by qPCR. $\mathbf{g}$ The correlation of HSF1 protein and miR455-3p in 12 pairs of fresh CRC tissues and adjacent non-tumor tissues was analyzed. $\mathbf{h}$ The effect of miR455-3p on viability of CRC cells was explored by MTS assay. $\mathbf{i}$ The effect of miR455-3p on apoptosis of CRC cells was analyzed using flow cytometry after PI and annexin V-FITC double staining. $\mathbf{j}$ Apoptosis of CRC cells treated with or without miR455-3p was determined by western blotting

m6A modification and its binding to METTL3 were decreased by the overexpression of wild type miR455-3p but not its mutant unable to bind to HSF1 mRNA 3'UTR (Fig. 5a and Additional file 2, Fig.S5A).
Interestingly, METTL3 depletion not only reduced m6A modification of HSF1 mRNA (Fig. 4e), but also enhanced the interaction of miR455-3p with HSF1 mRNA (Fig. 5b and Additional file 2, Fig.S5B), while the 
A

HSF1-3'UTR Wt: 5' UCACAGCCACACCUGGACUGAC

Hsa-miR455-3p: 3' CACAUAUACGGGUACCUGACG

B

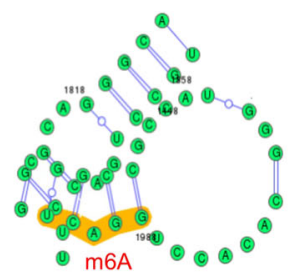

C

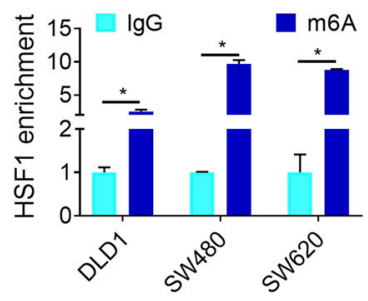

E

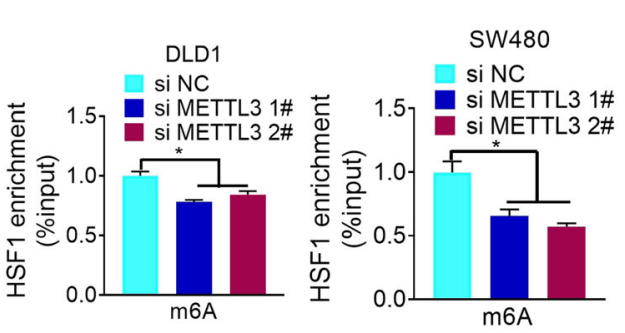

G

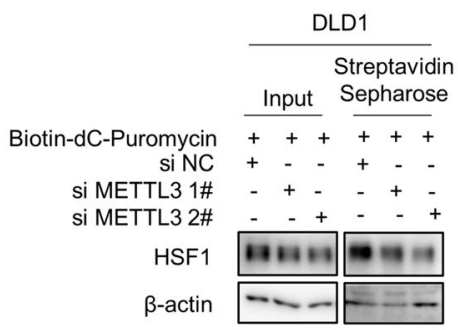

I

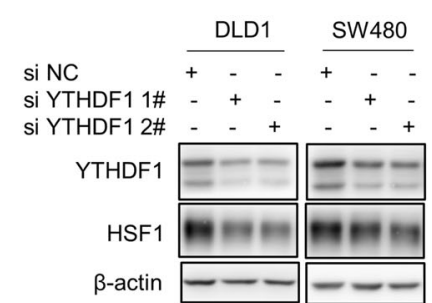

D

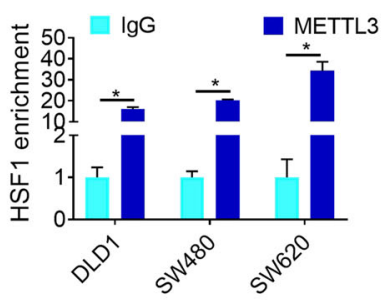

F

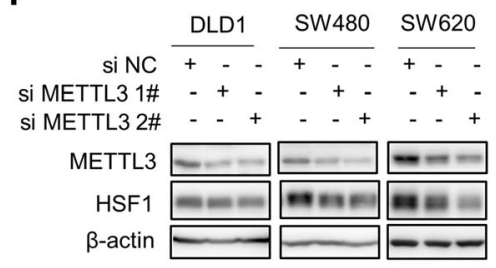

H

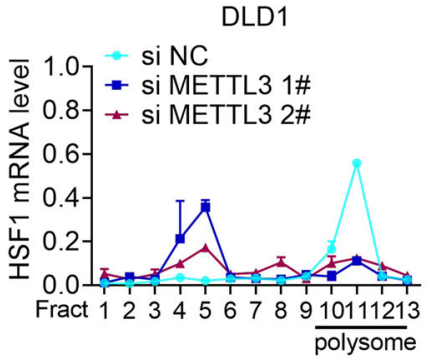

Fig. 4 m6A modification of HSF1 mRNA stimulates its protein translation. a The sites of HSF1 3'-UTR binding to the seed sequence of miR455-3p was consistent with m6A RNA modification elements "DRACH". b Bioinformatic prediction of m6A modification in 3'-UTR of HSF1 mRNA. c m6A modification of HSF1 mRNA was analyzed by meRIP ( $\left.{ }^{*} p<0.05\right)$. d Binding of METTL3 to HSF1 mRNA was detected by RIP $\left(^{*} p<0.05\right)$. e m6A modification of HSF1 mRNA with or without METTL3 depletion was analyzed by meRIP $\left({ }^{*} p<0.05\right)$. $\mathbf{f}$ The protein level of HSF1 before and after METTL3 depletion was detected by western blotting. $\mathbf{g}$ The effect of METTL3 knockdown on HSF1 synthesis was determined by western blotting after puromycin labeling. $\mathbf{h}$ Amount of HSF1 mRNA in various polysome fractions was analyzed by RT-PCR( $\left.{ }^{*} p<0.05\right)$. $\mathbf{i}$ The effect of YTHDF1 knockdown on HSF1 protein level was analyzed by western blotting

expression of mature and primary miR455-3p was not upregulated (Additional file 2, Fig.S5C-D). These results indicated that miR455-3p may compete with METTL3 for the m6A modification of HSF1 mRNA, thus inhibiting HSF1 protein translation. Furthermore, the binding of
miR455-3p to HSF1 mRNA was not changed by YTHDF1 deletion (Additional file 2, Fig.S5E), indicating that the translation repression of HSF1 mRNA was more likely to be mediated directly by the reduced $\mathrm{m} 6 \mathrm{~A}$ modification of HSF1. 
A

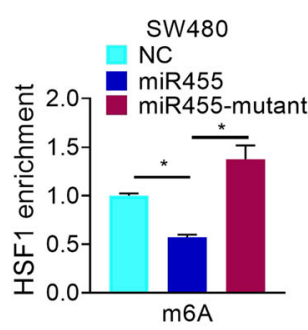

C

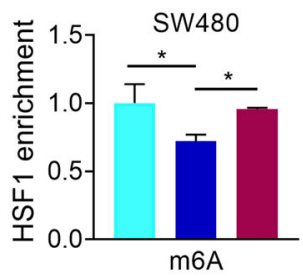

E

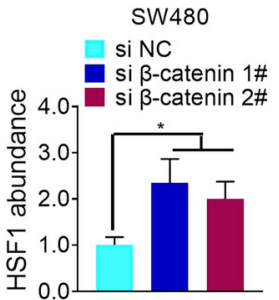

G

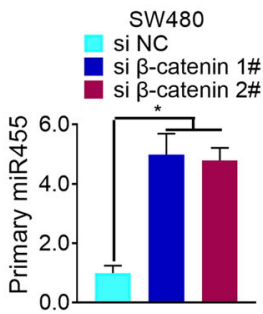

J

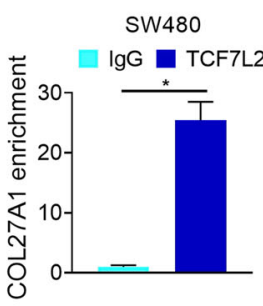

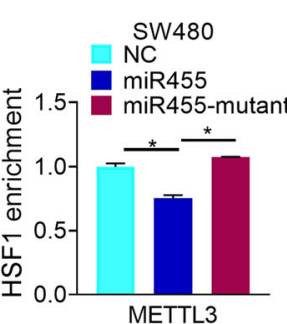

B

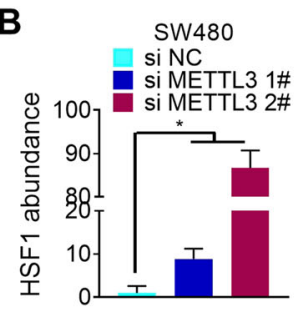

D

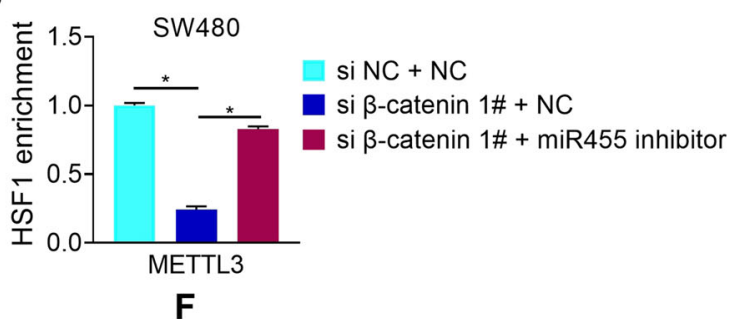

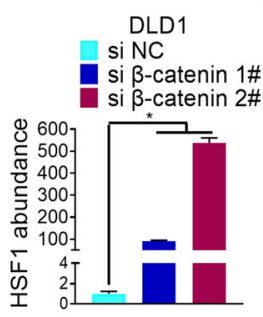

H
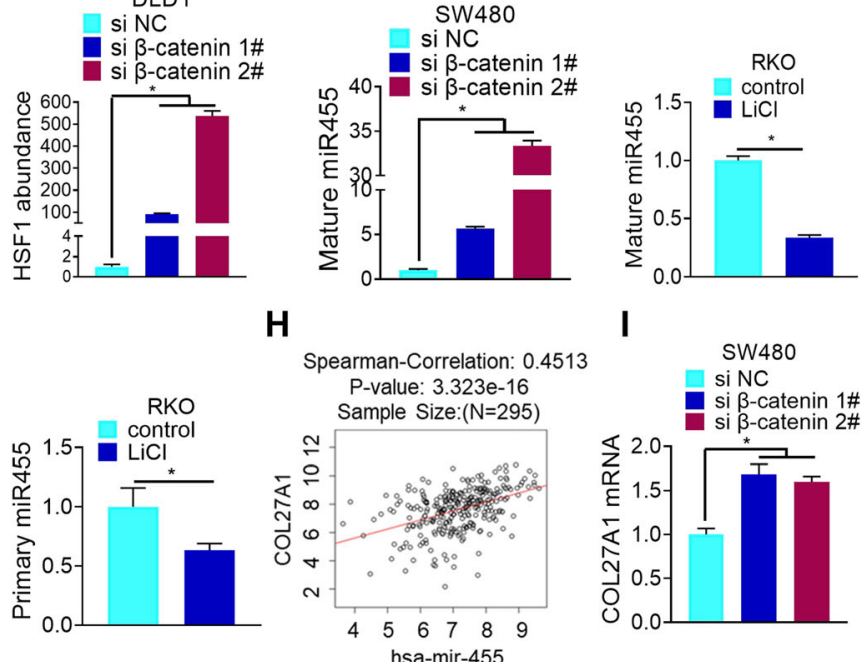

I

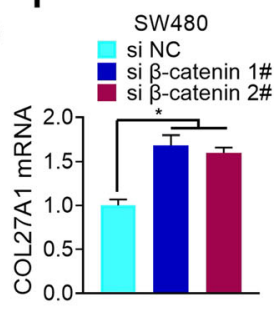

K Spearman-Correlation:-0.1139
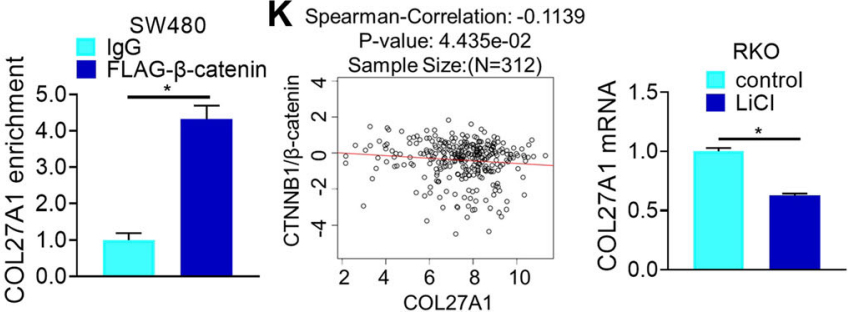

Fig. 5 - 3 -catenin suppresses miR455-3p to increase HSF1 mRNA m6A modification. a m6A modification and METTL3 interaction of HSF1 mRNA with WT or mutant of miR455-3p were analyzed by RIP. $\mathbf{b}$ The interaction between biotin-miR455-3p and HSF1 mRNA with or without METTL3 depletion was analyzed by biotin pull down. c The effect of miR455-3p inhibitor and/or $\beta$-catenin knockdown on m6A modification of HSF1 mRNA was analyzed by meRIP. $\mathbf{d}$ The effect of miR455-3p inhibitor and/or $\beta$-catenin knockdown on the interaction of METTL3 with HSF1 mRNA was analyzed by RIP. e The effect of $\beta$-catenin knockdown on interaction of miR455-3p and HSF1 mRNA was analyzed by biotin pull down. $\mathbf{f}$ and $\mathbf{g}$ The levels of mature $(\mathbf{f})$ and primary $(\mathbf{g})$ miR455-3p with $\beta$-catenin knockdown or LiCl treatment were determined by RT-PCR. $\mathbf{h}$ The correlation of COL27A1 and miR455 was analyzed in linkedomics (http://linkedomics.org/). $\mathbf{i}$ The effect of $\beta$-catenin depletion or LiCl on mRNA level of COL27A1 was analyzed by RT-PCR. $\mathbf{j}$ The interaction of $\beta$-catenin/TCF7L2 and HSF1 promoter was determined by ChIP. $\mathbf{k}$ The correlation of $\beta$ catenin protein expression with the RNA level of COL27A1 was detected by linkedomics (http://linkedomics.org/)

Indeed, miR455-3p inhibitor rescued $\beta$-catenin depletion-induced decrease of HSF1 mRNA m6A modification (Fig. 5c and Additional file 2, Fig.S5F). Meanwhile, the interaction of METTL3 with HSF1 mRNA was abrogated by depleting $\beta$-catenin (Fig. $5 \mathrm{~d}$ and Additional file 2, Fig.S5G), accompanied by the increased interaction of miR455-3p to HSF1 mRNA (Fig. 5e), and upregulation of mature (Fig. $5 \mathrm{f}$ and Additional file 2, Fig.S5H), 
precursor (Additional file 2, Fig.S5I) and primary miR4553p (Fig. $5 \mathrm{~g}$ and Additional file 2, Fig.S5J). In contrast, when $\beta$-catenin was upregulated by overexpression or $\mathrm{LiCl}$ treatment, both mature miR455-3p (Fig. $5 \mathrm{f}$ and Additional file 2, Fig.S5H) and primary miR455-3p (Fig. $5 \mathrm{~g}$ and Additional file 2, Fig.S5J) were downregulated.

Primary miR455-3p was derived from a pre-miRNA hairpin encoded in intron 10 of the collagen gene COL27A1 [28](Additional file 2, Fig.S5K). Actually, COL27A1 expression was significantly correlated with the expression of miR455 (http://linkedomics.org/) (Fig. 5h). Consistent with this, we observed COL27A1 mRNA levels were increased upon $\beta$-catenin depletion while decreased after $\mathrm{LiCl}$ treatment (Fig. 5i and Additional file 2, Fig.S5L). Moreover, $\beta$ catenin/TCF7L2 complex could interact with the promoter of COL27A1, while the pair of primers (Negative-chip-primer) at a position far away from the promoter region could not enrich COL27A1 (Fig. 5j and Additional file 2, Fig.S5M). Meanwhile, the protein expression of $\beta$-catenin was negatively correlated with RNA level of COL27A1 (http://linkedomics.org/) (Fig. 5k). These results indicated that the transcription of COL27A1 was inhibited by WNT/ $\beta$-catenin signaling, leading to decreased biogenesis of miR455-3p. Therefore, $\beta$-catenin facilitates the shift from miR455-3p binding to m6A modification in HSF1 mRNA by suppressing miR455-3p expression, eventually promoting HSF1 protein translation.

\section{Both genetic and chemical inhibition of HSF1 attenuate colorectal carcinogenesis in mice}

In light of these in vitro findings, we further explored the relevance of HSF1 to colorectal carcinogenesis in $\mathrm{Apc}^{\mathrm{min} /+}$ and $\mathrm{Apc}^{\mathrm{min} /+} \mathrm{HSF}^{+/-}$mice, since the interaction of mouse miR455-3p and mouse HSF1 mRNA seems to be well conserved (mouse miR455-3p seed sequence: CAGUCCA; the binding site in mouse HSF1 mRNA 3'-UTR: tggactg). The expression of HSF1 and its downstream target GLS1 were increased, while miR455-3p expression was reduced, in intestine tissues from $\mathrm{Apc}^{\mathrm{min} /+}$ mice compared with normal C57BL/6 mice (Fig. $6 a$ and b). After fed with high-fat diet for 3 months, these $\mathrm{Apc}^{\mathrm{min} /+}$ mice developed multiple tumors in the intestine (Fig. 6c). However, both the size and number of tumors were significantly reduced in $\mathrm{Apc}^{\mathrm{min} /+}$ mice treated with a chemical inhibitor of HSF1, KNK437 and $\mathrm{Apc}^{\mathrm{min} /+} \mathrm{HSF}^{+/-}$mice (Fig. 6d), accompanied by the downregulation of HSF1 targets (Fig. 6e). All of these results confirmed that HSF1 is a novel downstream target of $\mathrm{WNT} / \beta$-catenin signaling important to promote CRC development.

\section{Discussion}

Genetic changes in components of $\mathrm{WNT} / \beta$-catenin signaling such as deletion of the APC gene and CTNNB1 mutations have been frequently detected in many types of human cancers [29]. All of these mutations will eventually lead to the activation of $\mathrm{WNT} / \beta$-catenin signaling, mainly displayed as the accumulation of $\beta$-catenin in the nucleus to activate TCF/LEFs-driven transcription of socalled WNT responsive target genes including wellknown oncogenes such as c-MYC and cyclinD1 [30,31]. However, alternative functions of activated $\mathrm{WNT} / \beta$-catenin signaling were largely overlooked because of the overwhelming relevance of these well-known targets. For example, $\beta$-catenin played an important role in mitotic spindle orientation and cell migration through regulating cytoskeleton in a transcription-independent manner [32]. In this study, we revealed a new function of WNT/ $\beta$-catenin signaling in facilitating mRNA m6A modification and stimulating the synthesis of HSF1 protein, which can activate glutaminolysis to promote the pathogenesis of colorectal carcinogenesis [7].

Recently, RNA modifications such as m6A modification were important for fate decision of target mRNAs $[12,33]$. However, the regulation of mRNA m6A modification under various circumstances were largely unknown. We reported here that $\beta$-catenin can enhance the interaction of HSF1 mRNA with METTL3 to increase its m6A modification. As a result, the translation of HSF1 mRNA was activated and $\beta$-catenin expression was correlated with HSF1 expression in various cell lines and primary tissues. Recently, more and more nonclassical RNA binding proteins (RBPs) including $\beta$ catenin were found to interact with multiple mRNAs $[14,34]$. However, we failed to find the direct interaction of $\beta$-catenin with METTL3 or HSF1 mRNA (data not shown), thus excluding the direct recruitment of METT L3 by $\beta$-catenin. While the mechanism underlying specific interaction of METTL3 to HSF1 mRNA remains to be investigated, we found that miRNAs can affect the accessibility of HSF1 mRNA to METTL3. METTL3 can interact with HSF1 mRNA only when the abundance of miR455-3p was reduced. Once miR455-3p interacts with HSF1 mRNA by base-pairing, the interaction of METT L3 was greatly impaired. It has been reported that miRNA binding sites were remarkably enriched among m6A modification motifs [35]. Furthermore, overexpressing miRNAs significantly increased the association of target mRNAs with METTL3, whereas downregulating miRNA abundance significantly reduced METTL3 binding on mRNAs [35]. Unfortunately, the consequences of increased m6A modification on these mRNAs were not shown. It has been well-recognized that the interaction of miRNAs will lead to the degradation of target mRNAs or suppression of mRNA translation. In contrast, m6A modification can generate distinct consequences including stimulating mRNA translation, promoting or preventing mRNA degradation. Therefore, 
A

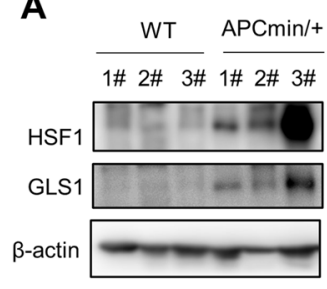

B

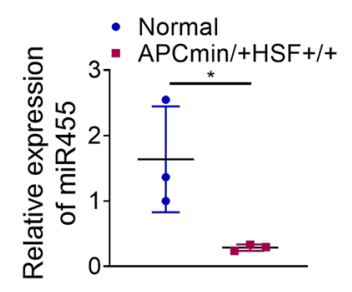

D $: W T$

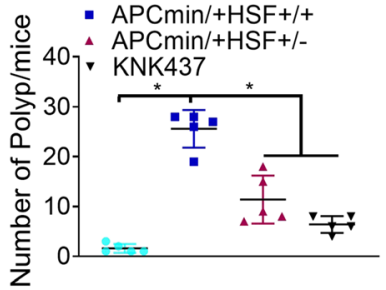

\section{C}
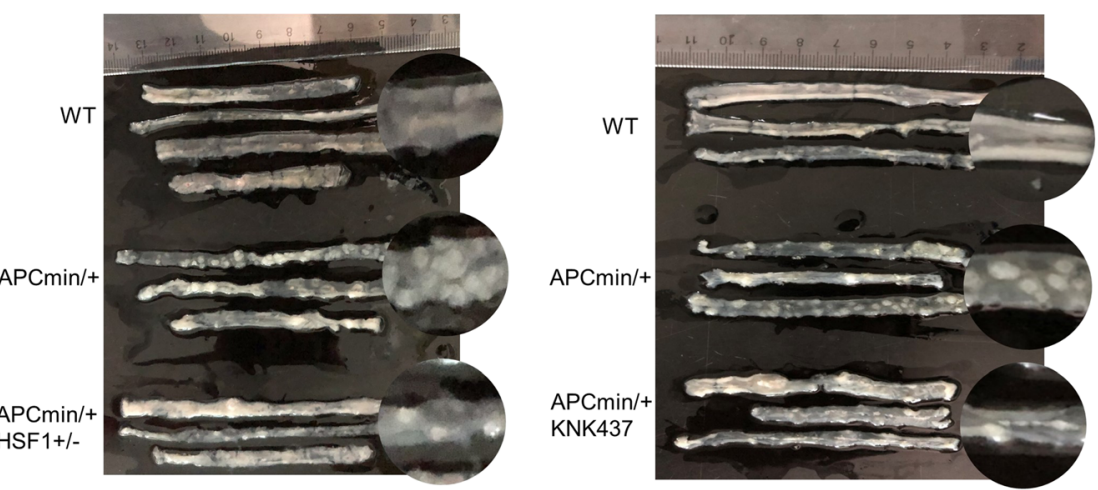

E

$$
\text { Normal }
$$

- APCmin/+HSF+/+

- APCmin/+HSF+/-
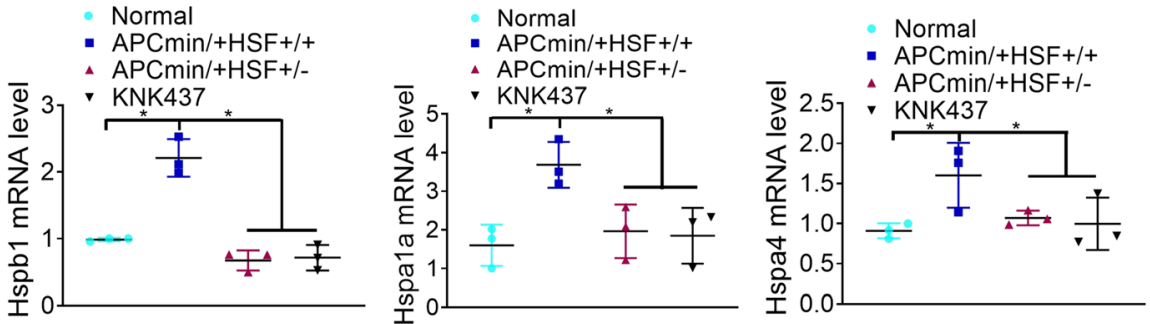

F
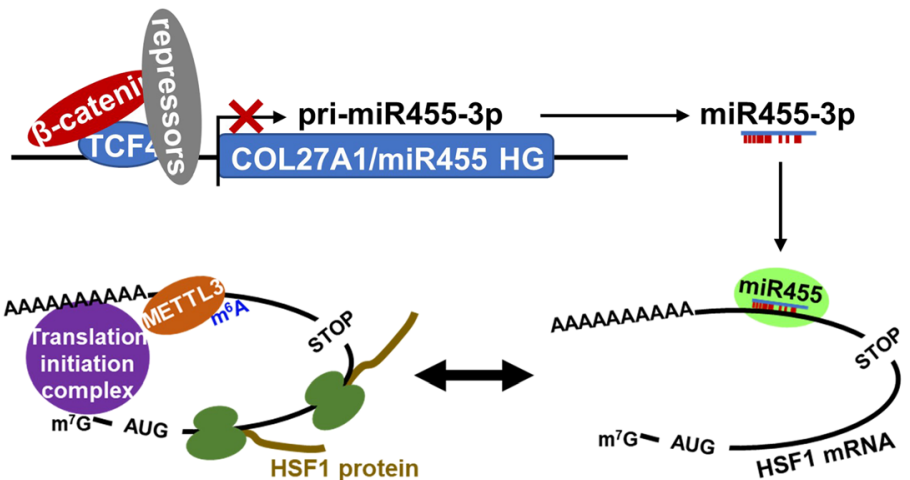

Fig. 6 Both genetic and chemical inhibition of HSF1 attenuate colorectal carcinogenesis driven by active Wnt signaling. a Expression of HSF1 protein in bowel tissue of APCmin/+ mice was analyzed by western blotting. $\mathbf{b}$ miR455-3p expression in bowel tissue of APCmin/+ mice was analyzed by RT-PCR. $\mathbf{c}$ and $\mathbf{d}$ The number of polyps per mouse in APCmin/+ and APCmin/+ mice when HSF1 was genetically knocked out or chemically inhibited mice was counted. e The downstream targets of HSF1 in APCmin/+ treated with KNK437 and APCmin/+HSF1+/- mice were analyzed by PT-PCR. Asterisks ${ }^{*}$ ) indicate a $P<0.05$. f Working model: When Wnt/ $\beta$-catenin was inactivated, the transcription of COL27A1, the host gene of miR455-3p (miR455HG), was increased so that more miR455-3p was generated to occupy HSF1 mRNA 3'-UTR and prevent it from METTL3-mediated m6A modification, thus repressing HSF1 translation. In contrast, upon Wnt/ $\beta$-catenin activation, miR455-3p generation was repressed so that HSF1 mRNA accessible for METTL3 binding and M6A modification. Eventually HSF1 translation was stimulated to promote colorectal carcinogenesis

miRNA-promoted m6A modification must be restricted in particular cells or circumstances. Generally, expression-suppressing miRNAs should repress m6A modifications promoting mRNA translation, just like what we presented here that miR455-3p inhibited m6A modification of HSF1 mRNA to impair its translation efficiency. Certainly, it remains to be investigated how miRNA binding exactly interfere the interaction with 
METLL3. MiRNA binding results in the formation of miRISC, which may impede METTL3 interaction. On the other hand, m6A modification once formed can alter the structure and conformation of mRNA, thus affecting the base-pairing with miRNAs [36]. Therefore, miRNAs and METTL3 can compete with each other to control the fate decision of mRNAs. Indeed, only wild type miR455-3p but not its mutant with mutations in the seed sequence, interacted with HSF1 mRNA and prevented METTL3 binding. When the increase of miR455$3 p$ was neutralized by miR455-3p inhibitor, $\beta$-catenin depletion cannot reduce m6A modification of HSF1 mRNA anymore.

As a result, the abundance of miR455-3p is critical to regulate m6A modification of HSF1 mRNA. Interestingly, we found that $\beta$-catenin inhibited the biogenesis of miR455-3p by suppressing the transcription of its host gene COL27A. While $\beta$-catenin was well-known to be a transcriptional co-activator, it can also function as a transcriptional repressor to directly repress gene transcription $[37,38]$. For example, $\beta$-catenin in complex with LEF1 repressed the transcription of Runx2 targets such as osteocalcin 2 [39]. Actually, we found more genes were downregulated after $\mathrm{LiCl}$ treatment than genes upregulated (Additional file 2, Fig.S6A). Similar to translational activation, transcriptional repression function of $\beta$-catenin depends on its interaction with TCF/LEF1 but recognizes a distinct TCF-binding motif, AGAWAW instead of CTTTGWWS [40]. Conversion of this unique motif to standard TCF-binding sites switched the mode of regulation from $\beta$-catenin-mediated repression to activation, indicating the importance of this motif to transcription inactivation. In consistence with the downregulation of COL27A1 expression by $\beta$-catenin, multiple such noncanonical TCF4-binding elements were found in its promoter region. When bound to these motifs by its HMG (high mobility group) domain, TCF can activate gene transcription in the absence of $\beta$-catenin. Upon the activation of WNT signaling, $\beta$-catenin interacted with TCF and repressed gene transcription although the binding of TCF to these motifs was not altered [41]. Other co-activators and co-repressors are likely to be involved in this allosteric regulation and warrants further investigations. Nevertheless, $\beta$-catenin/TCF complex could interact with other transcriptional co-repressors such as members of the Groucho family [42]. Alternatively, $\beta$-catenin/TCF complex might be able to inhibit the transactivation activity of other transcription factors interacted with the same promoter.

Taken together, $\beta$-catenin suppressed the biogenesis of miR455-3p to allow METTL3 binding for m6A modification of HSF1 mRNA, thus stimulating HSF1 mRNA translation. In cancer cells, HSF1 can drive a transcriptional program distinct from heat shock response to support malignant phenotypes [15, 43]. For instance, HSF1 can drive the transcription of PDK3 (Pyruvate Dehydrogenase Kinase 3) to promote glycolysis in chemo-resistant cancer cells [44]. It can also recruit DNMT3a to the promoter of miR137HG and repress the biogenesis of GLS1 (Glutaminase 1)-targeting miR137, thus upregulating GLS1 expression to activate mTOR and promote cancer development [7]. Currently, there are several ongoing clinical trials to evaluate the potential of targeting HSF1 for cancer treatment. Although WNT signaling has been well-known to be important for the development of CRC and many other cancers, no targeting drugs have been developed for clinical application. This study revealed HSF1 as a novel downstream target for $\beta$-catenin to promote cancer development, indicating that HSF1-targeting molecules could be tried for the intervention of human cancer driven by activated $\mathrm{WNT} / \beta$-catenin signaling.

\section{Conclusions}

In summary, $\beta$-catenin suppressed the biogenesis of HSF1-targeting miR455-3p to favor METTL3 binding and m6A modification of HSF1 mRNA, thus promoting HSF1 translation. HSF1 expression was upregulated in murine tumors driven by activated $\mathrm{WNT} / \beta$-catenin signaling and human CRC tissues. Genetic and chemical inhibition of HSF1 significantly attenuated the pathogenesis of CRC in mice. Targeting HSF1 is a potential strategy for the management of human cancers associated with activated $\mathrm{WNT} / \beta$-catenin signaling.

\section{Supplementary information}

Supplementary information accompanies this paper at https://doi.org/10. 1186/s12943-020-01244-z.

Additional file 1: Table S1. RNA oligonucleotide sequences. Table S2. Primer sequences.

Additional file 2: Supplemnetary Figures 1-6. Fig. S1. WNT/ $\beta$ catenin signaling activates HSF1. Fig. S2. $\beta$-catenin has no effects on the RNA and protein half-life of HSF1. Fig. S3. The effect of microRNAs on HSF1 expression in CRC. Fig. S4. m6A modification of HSF1 mRNA. Fig. S5. The effects of miR455-3p and m6A modification on HSF1. Fig. S6. Volcano plot displays differentially regulated genes upon LiCl treatment.

Additional file 3. The list of genes containing HSE in their promoters.

\section{Abbreviations}

CRC: Colorectal cancer; HSF1: Heat shock factor 1; HSE: Heat shock response elements; ChIP: Chromatin immunoprecipitation; LiCl: Lithium chloride; MEF: Mouse embryonic fibroblast; UTR: Untranslated region; AcetylCoA: Acetyl coenzyme A; TCA: Tricarboxylic acid; GLS1: Glutaminase 1; miRISC: miRNA-induced silencing complex; GSK3ß: Glycogen synthase kinase $3 \beta$; TCF/LEF: T cell-specific factor/lymphoid enhancer binding factor; m6A: N6-methyladenosine; IHC: Immunohistochemical; meRIP: m6A RNA immunoprecipitation; PCR: Polymerase chain reaction

\section{Acknowledgments}

We thank members of our laboratories for their suggestions. We also thank the staff members at the Core facilities at the Zhejiang University School of Medicine for their assistance in polysome profiling essays. 


\section{Authors' contributions}

$S P, F L, L J, D D, Z L, J L, W C, L J, L L, Q Z$ and $S R$ performed experiments and analyzed data. WX and JH designed the project. SP, WX and JH wrote the manuscript. The author(s) read and approved the final manuscript.

\section{Funding}

This work was supported by High level health innovative talents program in Zhejiang, Natural Science Foundation of Zhejiang (LZ18H160001;

LZ17H60003) and National Natural Science Foundation of China (91740106; 81772944; 8207110242; 81672360).

\section{Availability of data and materials}

The authors declare that all the other data supporting the findings of this study are available within the article and its additional files and from the corresponding author upon reasonable request. The data for highthroughput sequencing are deposited at GEO under the accession number GSE151119.

\section{Ethics approval and consent to participate}

The research was approved by the Ethics Committee of Sir Run Run Shaw Hospital, Zhejiang University School of Medicine. Animal care and experiments were conducted in compliance with Institutional Animal Care and Use Committee and $\mathrm{NIH}$ guidelines.

\section{Consent for publication}

If this article is accepted, we will agree to publish it and transfer the copyright to academic journals and your publishing company.

\section{Competing interests}

The authors have no conflicts of interest to disclose

\section{Author details}

${ }^{1}$ Department of Medical Oncology, Cancer Institute of Zhejiang University, Sir Run Run Shaw Hospital, School of Medicine, Zhejiang University, Hangzhou, China. ${ }^{2}$ Labortary of Cancer Biology, Key Lab of Biotherapy in Zhejiang, Sir Run Run Shaw Hospital, School of Medicine, Zhejiang University, Hangzhou, China. ${ }^{3}$ Department of pathology, People's Hospital of Dongyang, Zhejiang, China.

\section{Received: 4 February 2020 Accepted: 12 August 2020}

Published online: 24 August 2020

\section{References}

1. Siegel RL, Miller KD, Jemal A. Cancer statistics, 2019. CA Cancer J Clin. 2019; 69(1):7-34.

2. Rosenbluh J, Nijhawan D, Cox AG, Li X, Neal JT, Schafer EJ, Zack TI, Wang X, Tsherniak A, Schinzel AC, et al. beta-catenin-driven cancers require a YAP1 transcriptional complex for survival and tumorigenesis. Cell. 2012;151(7): 1457-73.

3. Morris JP, Yashinskie JJ, Koche R, Chandwani R, Tian S, Chen CC, Baslan T, Marinkovic ZS, Sanchez-Rivera FJ, Leach SD, et al. alpha-Ketoglutarate links p53 to cell fate during tumour suppression. Nature. 2019:573(7775):595-9.

4. Wang Y, Xia Y, Lu Z. Metabolic features of cancer cells. Cancer Commun (Lond). 2018;38(1):65.

5. Hay N. Reprogramming glucose metabolism in cancer: can it be exploited for cancer therapy? Nat Rev Cancer. 2016;16(10):635-49.

6. Altman BJ, Stine ZE, Dang CV. From Krebs to clinic: glutamine metabolism to cancer therapy. Nat Rev Cancer. 2016;16(10):619-34.

7. Li J, Song P, Jiang T, Dai D, Wang H, Sun J, Zhu L, Xu W, Feng L, Shin WY, et al. Heat shock factor 1 epigenetically stimulates Glutaminase-1dependent mTOR activation to promote colorectal carcinogenesis. Mol Ther. 2018;26(7):1828-39.

8. Eulalio A, Huntzinger E, Izaurralde E. Getting to the root of miRNA-mediated gene silencing. Cell. 2008;132(1):9-14.

9. Choe J, Lin S, Zhang W, Liu Q, Wang L, Ramirez-Moya J, Du P, Kim W, Tang S, Sliz P, et al. mRNA circularization by METTL3-elF3h enhances translation and promotes oncogenesis. Nature. 2018;561(7724):556-60.

10. Jonas $\mathrm{S}$, Izaurralde E. Towards a molecular understanding of microRNAmediated gene silencing. Nat Rev Genet. 2015;16(7):421-33.

11. Mathonnet G, Fabian MR, Svitkin YV, Parsyan A, Huck L, Murata T, Biffo S, Merrick WC, Darzynkiewicz E, Pillai RS, et al. MicroRNA inhibition of translation initiation in vitro by targeting the cap-binding complex elF4F. Science. 2007:317(5845):1764-7.

12. Wang X, Zhao BS, Roundtree IA, Lu Z, Han D, Ma H, Weng X, Chen K, Shi H, He C. N(6)-methyladenosine modulates messenger RNA translation efficiency. Cell. 2015;161(6):1388-99.

13. Chasse $H$, Boulben S, Costache V, Cormier P, Morales J. Analysis of translation using polysome profiling. Nucleic Acids Res. 2017;45(3):e15.

14. Zhu $L$, Zhu $Y$, Han $S$, Chen $M$, Song $P$, Dai $D$, Xu W, Jiang T, Feng $L$, Shin $V Y$, et al. Impaired autophagic degradation of IncRNA ARHGAP5-AS1 promotes chemoresistance in gastric cancer. Cell Death Dis. 2019;10(6):383.

15. Mendillo ML, Santagata S, Koeva M, Bell GW, Hu R, Tamimi RM, Fraenkel E, Ince TA, Whitesell L, Lindquist S. HSF1 drives a transcriptional program distinct from heat shock to support highly malignant human cancers. Cell. 2012;150(3):549-62.

16. Lamb J, Crawford ED, Peck D, Modell JW, Blat IC, Wrobel MJ, Lerner J, Brunet JP, Subramanian A, Ross KN, et al. The connectivity map: using geneexpression signatures to connect small molecules, genes, and disease. Science. 2006;313(5795):1929-35.

17. Barham W, Frump AL, Sherrill TP, Garcia CB, Saito-Diaz K, VanSaun MN, Fingleton B, Gleaves L, Orton D, Capecchi MR, et al. Targeting the Wht pathway in synovial sarcoma models. Cancer Discov. 2013;3(11):1286-301.

18. Watanabe K, Biesinger J, Salmans ML, Roberts BS, Arthur WT, Cleary M, Andersen B, Xie X, Dai X. Integrative ChIP-seg/microarray analysis identifies a CTNNB1 target signature enriched in intestinal stem cells and colon cancer. PLoS One. 2014;9(3):e92317.

19. Sato Y, Murakami T, Funatsuki H, Matsuba S, Saruyama H, Tanida M. Heat shock-mediated APX gene expression and protection against chilling injury in rice seedlings. J Exp Bot. 2001;52(354):145-51.

20. Zamdborg L, Ma P. Discovery of protein-DNA interactions by penalized multivariate regression. Nucleic Acids Res. 2009;37(16):5246-54.

21. Liu J, Xu Y, Stoleru D, Salic A. Imaging protein synthesis in cells and tissues with an alkyne analog of puromycin. Proc Natl Acad Sci U S A. 2012;109(2): 413-8.

22. Lewis BP, Burge CB, Bartel DP. Conserved seed pairing, often flanked by adenosines, indicates that thousands of human genes are microRNA targets. Cell. 2005;120(1):15-20.

23. Bartosovic M, Molares HC, Gregorova P, Hrossova D, Kudla G, Vanacova S. N6-methyladenosine demethylase FTO targets pre-mRNAs and regulates alternative splicing and 3'-end processing. Nucleic Acids Res. 2017;45(19): 11356-70.

24. Harper JE, Miceli SM, Roberts RJ, Manley JL. Sequence specificity of the human mRNA N6-adenosine methylase in vitro. Nucleic Acids Res. 1990; 18(19):5735-41.

25. Liu J, Yue Y, Han D, Wang X, Fu Y, Zhang L, Jia G, Yu M, Lu Z, Deng X, et al. A METTL3-METTL14 complex mediates mammalian nuclear RNA N6adenosine methylation. Nat Chem Biol. 2014;10(2):93-5.

26. Wang X, Feng J, Xue Y, Guan Z, Zhang D, Liu Z, Gong Z, Wang Q, Huang J, Tang C, et al. Structural basis of N(6)-adenosine methylation by the METTL3METTL14 complex. Nature. 2016;534(7608):575-8.

27. Du Y, Hou G, Zhang H, Dou J, He J, Guo Y, Li L, Chen R, Wang Y, Deng $R$, et al. SUMOylation of the m6A-RNA methyltransferase METTL3 modulates its function. Nucleic Acids Res. 2018;46(10):5195-208.

28. Lalevee S, Lapaire O, Buhler M. miR455 is linked to hypoxia signaling and is deregulated in preeclampsia. Cell Death Dis. 2014;5:e1408.

29. Kandoth C, McLellan MD, Vandin F, Ye K, Niu B, Lu C, Xie M, Zhang Q, McMichael JF, Wyczalkowski MA, et al. Mutational landscape and significance across 12 major cancer types. Nature. 2013;502(7471):333-9.

30. He TC, Sparks AB, Rago C, Hermeking H, Zawel L, da Costa LT, Morin PJ, Vogelstein B, Kinzler KW. Identification of c-MYC as a target of the APC pathway. Science. 1998;281(5382):1509-12.

31. Tetsu O, McCormick F. Beta-catenin regulates expression of cyclin D1 in colon carcinoma cells. Nature. 1999;398(6726):422-6.

32. Gomez-Orte E, Saenz-Narciso B, Moreno S, Cabello J. Multiple functions of the noncanonical Wnt pathway. Trends Genet. 2013;29(9):545-53.

33. Zhou J, Wan J, Shu XE, Mao Y, Liu XM, Yuan X, Zhang X, Hess ME, Bruning JC, Qian SB. N(6)-Methyladenosine guides mRNA alternative translation during integrated stress response. Mol Cell. 2018;69(4):636-47 e637.

34. Kim I, Kwak H, Lee HK, Hyun S, Jeong S. beta-catenin recognizes a specific RNA motif in the cyclooxygenase-2 mRNA 3'-UTR and interacts with HuR in colon cancer cells. Nucleic Acids Res. 2012;40(14):6863-72. 
35. Chen T, Hao YJ, Zhang Y, Li MM, Wang M, Han W, Wu Y, Lv Y, Hao J, Wang $\mathrm{L}$, et al. $\mathrm{m}(6)$ a RNA methylation is regulated by microRNAs and promotes reprogramming to pluripotency. Cell Stem Cell. 2015;16(3):289-301.

36. Roost C, Lynch SR, Batista PJ, Qu K, Chang HY, Kool ET. Structure and thermodynamics of N6-methyladenosine in RNA: a spring-loaded base modification. J Am Chem Soc. 2015;137(5):2107-15.

37. Meng Q, Mongan M, Wang J, Xia Y. Repression of MAP 3K1 expression and JNK activity by canonical Wnt signaling. Dev Biol. 2018;440(2):129-36.

38. Smartt HJ, Greenhough A, Ordonez-Moran P, Talero E, Cherry CA, Wallam CA, Parry L, Al Kharusi M, Roberts HR, Mariadason JM, et al. beta-catenin represses expression of the tumour suppressor 15-prostaglandin dehydrogenase in the normal intestinal epithelium and colorectal tumour cells. Gut. 2012;61(9):1306-14.

39. Kahler RA, Westendorf JJ. Lymphoid enhancer factor-1 and beta-catenin inhibit Runx2-dependent transcriptional activation of the osteocalcin promoter. J Biol Chem. 2003;278(14):11937-44.

40. Hoverter NP, Waterman ML. A Wnt-fall for gene regulation: repression. Sci Signal. 2008; (39):pe43.

41. Zhang CU, Blauwkamp TA, Burby PE, Cadigan KM. Wnt-mediated repression via bipartite DNA recognition by TCF in the Drosophila hematopoietic system. PLoS Genet. 2014;10(8):e1004509.

42. Brantjes H, Roose J, van De Wetering M, Clevers H. All Tcf HMG box transcription factors interact with Groucho-related co-repressors. Nucleic Acids Res. 2001;29(7):1410-9.

43. Yang T, Ren C, Lu C, Qiao P, Han X, Wang L, Wang D, Lv S, Sun Y, Yu Z. Phosphorylation of HSF1 by PIM2 induces PD-L1 expression and promotes tumor growth in breast Cancer. Cancer Res. 2019;79(20):5233-44.

44. Xu J, Shi Q, Xu W, Zhou Q, Shi R, Ma Y, Chen D, Zhu L, Feng L, Cheng AS, et al. Metabolic enzyme PDK3 forms a positive feedback loop with transcription factor HSF1 to drive chemoresistance. Theranostics. 2019;9(10); 2999-3013.

\section{Publisher's Note}

Springer Nature remains neutral with regard to jurisdictional claims in published maps and institutional affiliations.

Ready to submit your research? Choose BMC and benefit from:

- fast, convenient online submission

- thorough peer review by experienced researchers in your field

- rapid publication on acceptance

- support for research data, including large and complex data types

- gold Open Access which fosters wider collaboration and increased citations

- maximum visibility for your research: over $100 \mathrm{M}$ website views per year

At $\mathrm{BMC}$, research is always in progress.

Learn more biomedcentral.com/submissions 